\title{
EDITORIAL \\ ELECTRONIC JOURNAL WITH OPEN ACCESS: A TECHNOLOGICAL LEAP
}

The Faculty of Health at Universidad del Valle determined the conformation, functions, and competencies of the Scientific and Editorial Committees of the Colombia Médica journal (Resolution 099, July 07, $2009 \mathrm{HCF}$ ), permitting the naming of the Committees for the Journal and the opening of the internal call to name the Editor-in-Chief and the Associate Editors. Internal regulations institutionally define the types of publications of greatest interest, the frequency of each publication, and types of articles in regular and supplementary numbers, internal operations aspects; define stimuli for excellence in articles published with an award and editorial sanctions for plagiarism of intellectual property and redundant publication.

In 1995, Colombia Médica adopted the web publication, now in 2010, fifteen years later, we have adopted an agile and secure electronic management and publication system with open access that will permit editors, peers, and authors to work together from anywhere in the world, it will allow greater efficiency in real time with significant reduction of administrative costs. This system is currently used by 235 journals in the world, achieving more expeditious indexation of their articles, which is attractive for local researchers and for the international scientific community. For our Journal this open electronic system is a true technological leap.

The visibility of Colombia Médica has been traditionally good, given that it is indexed in 23 international data bases including the Institute for Scientific Information-ISI Thomson web of knowledge, and because it is a free journal that is easily accessed via the web. International Observatories have reported an increase in the number of downloads of complete articles by three times in the last year, which we feel is correlated to the four-fold increase of complete articles published in English. These facts, along with growing publication requests by authors from five continents are a stimulus for the Journal to publish a greater number of complete articles in English.

The number of electronic downloads reported by our counters and by international observatories quickly bring us closer to the average for journals published by ELSEVIER, recognized for their highest standards of scientific visibility and quality in the world. Due to this we are calling for an exchange of ideas and experiences at our home, Universidad del Valle, during a national meeting of editors of health sciences journals, which undoubtedly permit our journals fulfill their goals.

The first two numbers for this year report articles of interest for public health, like the critical analysis of the effectiveness of health promotion in Latin America, health services for adolescents, and sexual health for adolescents. The articles also report research studies in basic sciences, qualitative research, report of the Colombian Muisca Mummy (S010-IX mummy), inflammatory response in children with severe malnutrition, population genetic studies, case reports, and brief communications. We are convinced that with the new open editorial system, the growing international presence of our publications, and reports on themes of greater pertinence in different areas of health we are set to compete in the difficult and demanding world of scientific disclosure.

JULIAN ALBERTO HERRERA, MD

Emeritus Professor and Head

Department of Family Medicine Editor-in-Chief Colombia Médica 